\title{
A ESTRATÉGIA SAÚDE DA FAMÍLIA E A ESCOLA NA EDUCAÇÃO SEXUAL: UMA PERSPECTIVA DE INTERSETORIALIDADE
}

\author{
THE FAMILY HEALTH STRATEGY AND THE SCHOOL IN SEX \\ EDUCATION: AN INTERSECTORAL PERSPECTIVE
}

\author{
LA ESTRATEGIA SALUD DE LA FAMILIA Y LA ESCUELA EN LA EDUCACIÓN \\ SEXUAL: UNA PERSPECTIVA DE INTERSECTORIALIDAD
}

\author{
Aldrin de Sousa Pinheiro ${ }^{1}$ \\ Lucia Rejane Gomes da Silva ${ }^{2}$ \\ Maria Berenice Alho da Costa Tourinho ${ }^{3}$
}

Resumo A pesquisa analisou como o trabalho de educação sexual de adolescentes e jovens é desenvolvido na perspectiva da intersetorialidade de saúde e educação. Foram levantadas as características pedagógicas e metodológicas usadas por professores e profissionais da Estratégia Saúde da Família de um município do sul da Amazônia ocidental, assim como as perspectivas de interseção da escola com os serviços de saúde para a educação sexual. A pesquisa foi realizada no período de maio a setembro de 2013. Optou-se pela abordagem qualitativa. Após entrevista semiestruturada, utilizou-se a análise de conteúdo para o levantamento das categorias temáticas. $\mathrm{O}$ trabalho de educação sexual caracterizou-se por atividades pontuais motivadas pela demanda. A família foi considerada a principal responsável pela educação sexual, e o despreparo profissional mostrou-se fator importante para a não realização desse tipo de educação. As perspectivas intersetoriais pontuadas pelos participantes ficaram limitadas às ações já existentes na prática, como palestras e projetos, dentre outras. A intersetorialidade para o trabalho de educação sexual parece transitar no campo das ideias, amarrada aos discursos. Apesar de iniciativas governamentais a estimularem, essas perspectivas não têm dado conta da complexidade que envolve sua legitimação. É necessário que novas estratégias para o trabalho da educação sexual sejam discutidas.

Palavras-chave sexualidade; educação sexual escolar; políticas públicas; intersetorialidade.
Abstract The study analyzed how sex education is provided to adolescents and young people from the perspective of the intersectoriality of health and education. The pedagogical and methodological characteristics used by teachers and professionals of the Family Health Strategy of a municipality in southern western Amazônia were surveyed, as were the perspectives of intersecting the school with health services for sex education. The survey was conducted between May and September 2013. A qualitative approach was used. After a semi-structured interview, content analysis was used to survey the thematic categories. Sex education was characterized by specific activities motivated by demand. The family was considered the main element responsible for sex education, and a lack of professional preparedness proved to be an important factor for this type of education not being provided. The intersectoral perspectives pointed out by the participants were limited to the actions already existing in practice, such as lectures and projects, among others. Intersectoriality for sex education seems to transit in the field of ideas, tied to the discourses. Although government initiatives encourage it, these perspectives have failed to account for the complexity involved in its legitimation. New strategies must be discussed for sex education.

Keywords sexuality; school sex education; public policy; intersectoriality. 


\section{Introdução}

A adolescência vem sendo encarada no cenário brasileiro e mundial como um período de intensas e abruptas mudanças físicas, emocionais e principalmente comportamentais. Uma fase de sonhos, pensamentos mágicos sobre a realidade, que conduz à ideia de uma proteção natural a agressões e riscos externos. Com o advento da Aids e o emergir das doenças sexualmente transmissíveis (DSTs) - causas importantes de morbimortalidade no Brasil -, o sistema de saúde ampliou a visão dos fatores de risco associados às doenças transmissíveis e trouxe à discussão a questão da vulnerabilidade e sexualidade (Brasil, 2009). As medidas de enfrentamento dos problemas emergentes da adolescência ultrapassaram as fronteiras da saúde e alcançaram proporções intersetoriais importantes.

$\mathrm{Na}$ educação, a novidade se deu pela inserção da saúde e da orientação sexual $^{4}$ como 'temas transversais' por meio dos Parâmetros Curriculares Nacionais (PCNs) em 1998 (Brasil, 1998). Assim, o Estado trouxe para a escola a responsabilidade de desenvolver uma ação crítica, reflexiva e educativa para a promoção da saúde de crianças e adolescentes, dividindo essa tarefa com a família (Altmann, 2001). Essa autora ressalva que o tema não é novo no contexto escolar, mas ganhou força, maior visibilidade e inserção nos currículos escolares devido ao contexto histórico associado à dimensão epidemiológica e às mudanças no padrão de comportamento sexual da sociedade brasileira.

No setor saúde, a educação sexual ganhou espaço a partir das políticas públicas de promoção norteadas pela Lei Orgânica da Saúde (lei n. 8.080, de 1990) (Brasil, 1990). A educação sexual como estratégia de saúde pública pode interferir - e contribuir diretamente - na redução dos indicadores de morbimortalidade que atingem jovens e adolescentes, como as taxas de mortalidade materna e perinatal (Silva, 2011).

Na perspectiva do trabalho intersetorial, não se pode afastar da discussão as formas como se desenvolvem os processos de trabalho em cada setor envolvido. No tocante ao trabalho intersetorial da educação sexual entre saúde e educação, formulamos dois questionamentos, para os quais buscamos respostas: como a educação sexual é desenvolvida no ambiente escolar e nas equipes de saúde da família? Quais as perspectivas dos profissionais da saúde e educação para o desenvolvimento do trabalho intersetorial?

Apesar de nos últimos anos os investimentos públicos e o fomento às políticas intersetoriais sinalizarem um olhar otimista e um momento de avanço para a implementação do trabalho de educação sexual de jovens e adolescentes, a prática precisa ser investigada, para que de forma sistemática a educação sexual seja pensada, planejada e executada de forma articulada entre os entes 
e equipamentos sociais disponíveis, como a escola e as unidades de saúde da família. De acordo com Inojosa (2001, p. 105), a

intersetorialidade consiste na articulação de saberes e experiências no planejamento, realização e na avaliação de ações, com o objetivo de se alcançar resultados integrados em situações complexas, visando a um efeito sinérgico no desenvolvimento social.

A implementação das políticas públicas sociais para os setores saúde e educação pode contribuir para a mudança da abordagem da sexualidade de um modelo biológico e psicológico para uma abordagem pluralista e ampliada (Aquino, 1997).

O estudo aqui apresentado se propôs a analisar como o trabalho de educação sexual de adolescentes e jovens é desenvolvido na perspectiva da intersetorialidade entre saúde e educação; conhecer as características pedagógicas e metodológicas utilizadas; e levantar as perspectivas de interseção entre a escola e o serviço de saúde no desenvolvimento das atividades de educação sexual.

\section{O percurso metodológico da análise sobre o trabalho de educação sexual e a perspectiva da intersetorialidade}

Tratou-se de uma pesquisa com abordagem qualitativa, ${ }^{5}$ tendo em vista o seu caráter indutivo e as significações das pessoas para o desvelamento do objeto (Silveira e Córdova, 2009). Na abordagem qualitativa, o que se propõe é o saber como se faz, com o que se faz, e não o quanto se faz.

O universo de participantes nos estabelecimentos da pesquisa foi composto por enfermeiros e médicos de quatro equipes de saúde da família (EqSFs) e professores de uma escola municipal de ensino fundamental, localizados no município de Porto Velho, capital do estado de Rondônia, totalizando 68 (sessenta professores e oito profissionais de saúde). Participaram do estudo trinta professores da escola e sete profissionais das EqSFs, totalizando 37 profissionais, os quais assinaram o termo de consentimento livre e esclarecido. Os principais motivos para a não aceitação em participar da pesquisa foram a falta de tempo e a de interesse pelo assunto.

Os locais selecionados representaram a realidade das escolas de ensino fundamental e das unidades de saúde da família das diversas zonas do município quanto a organização e público atendido pela composição dos territórios, além dos programas desenvolvidos, como o Programa de Saúde na Escola.

A coleta de dados ocorreu de maio a setembro de 2013 por meio de entrevista semiestruturada utilizando-se um roteiro adaptado de Silva (2011), com o mesmo conteúdo e identificações diferentes: um para os profissionais da escola e outro para os profissionais de saúde. Os professores e os profissionais 
de saúde foram informados e sensibilizados sobre a pesquisa por meio de reuniões. Optou-se também pela utilização do diário de campo a fim de registrar impressões a respeito da dinâmica das unidades, falas e expressões importantes, bem como incidentes críticos durante o contato com os profissionais.

Para a organização dos dados e das respostas de cada participante da pesquisa, aos professores da escola foi atribuída a identificação P (P1, P2 etc.), e aos profissionais das equipes de saúde da família, a identificação $S$ (S1, S2 etc.). Os dados foram classificados e compilados ainda quando estavam sendo coletados, evidenciando os seus aspectos mais frequentes para que possibilitassem uma análise de conteúdo na modalidade de análise temática. Conforme Bardin (2009, p. 33), a análise de conteúdo é "um conjunto de técnicas de análise das comunicações", com a finalidade de atender aos objetivos de pesquisa propostos. Ela permite conhecer os núcleos de sentido, de forma que sua frequência possa significar algo do objetivo analítico escolhido.

Com relação à análise dos dados coletados, consideraram-se as etapas: pré-análise, exploração do material ou codificação e tratamento dos resultados, inferência e interpretação, propostas por Bardin (2009) para a análise de conteúdo. As categorias temáticas emergiram dos núcleos de sentido encontrados nas respostas dos participantes.

O referencial teórico que subsidiou a análise dos dados pautou-se na contribuição de autores que abordam a educação sexual na perspectiva da aceitação e do fomento de um protagonismo adolescente e do compromisso das instituições públicas de saúde e educação com a formação cidadã. Autores que tratam deste tema com essa abordagem são Valladares (2005), Foucault (2006), Figueiró (2004, 2009), Aquino (1997), Silva (2011) e Altmann (2001, 2007).

A pesquisa foi aprovada pelo Comitê de Ética em Pesquisa do Núcleo de Saúde da Fundação Universidade Federal de Rondônia (Certificado de Apresentação para Apreciação Ética (CAAE) n. 08487612.0.0000.5300).

\section{As respostas de professores e profissionais das equipes de saúde da família: achados relevantes e categorias temáticas relacionadas}

Dentre os professores da escola, vinte eram mulheres e dez homens. Em relação à idade, variou entre 23 e 54 anos. Quanto à formação, apenas um participante não respondeu; os demais tinham todos ensino superior. Entre os participantes das equipes de saúde da família, a predominância foi do sexo feminino (seis profissionais), com apenas um do sexo masculino. Três profissionais eram enfermeiras, três médicas e um médico; apenas uma enfermeira não participou do estudo por estar de férias. A idade variou entre 27 e 50 anos.

Das respostas analisadas, emergiram quatro categorias temáticas descritas e analisadas a seguir. 


\section{A vontade de saber como ponto positivo para o trabalho de educação sexual}

Para os participantes do estudo, a curiosidade dos adolescentes e jovens em conhecer a sexualidade e sexo atua como fator positivo e de facilidade para o trabalho de educação sexual, como evidenciado nas falas a seguir:

A facilidade ocorre quando o adolescente expõe sua dúvida e fazemos o gancho para abordar o tema (S5).

É fácil abordar quando o paciente fala. A gente falar é mais difícil (S3).

A facilidade para o trabalho em razão da curiosidade emerge como uma resposta à demanda dos alunos, característica peculiar no trabalho em saúde. Na prática do trabalho de educação sexual referida pelos profissionais da EqSF, o momento da consulta foi a estratégia mais amplamente utilizada, particularidade comum nos serviços de saúde, que têm seu funcionamento baseado na demanda espontânea e programada (Faria e Campos, 2012).

Esse tipo de abordagem e estratégia utilizada pela escola e pelos profissionais da EqSF é denominado por Figueiró (2009) na análise dos PCNs como uma forma 'extraprogramação' do trabalho de educação sexual. Nesta, todo e qualquer professor (estendendo aos profissionais da EqSF, pois também trabalham a temática) sem planejamento anterior aproveita uma situação, fato espontâneo, para ensinar, discutir ou transmitir uma mensagem sobre a sexualidade.

Figueiró (2009) também pontua outra característica de abordagem, a qual define como 'dentro da programação', em que o conteúdo da sexualidade proposto é organizado e planejado. Essa característica foi relatada apenas por um dos participantes, o que nos leva a pensar em um baixo planejamento sistemático para o desenvolvimento da temática.

Apesar da curiosidade característica dos adolescentes e jovens, em diversas respostas dos professores foi possível observar, em divergência em relação a outros posicionamentos, certa negação ou repressão do discurso (Foucalt, 2006) caracterizada pela ausência de abordagem da temática na prática da escola, como destacaram as falas a seguir:

Não utilizo nenhuma [estratégia de ensino], pois não abordo o tema (P15).

Até onde eu sei a escola não trabalha a educação sexual (P17).

Não fazemos essa abordagem, não sei como começar (P11).

A negação pode estar relacionada com o que Valladares (2005) pontua como o não entendimento do sentido da transversalidade no contexto da educação 
sexual. A negação e a eventualidade do desenvolvimento do trabalho refletem algo extremamente importante no contexto pedagógico da educação sexual: a ausência de planejamento para trabalhá-la.

No contexto da atenção básica, ainda há dificuldades na implantação e implementação de ações educativas destinadas aos adolescentes e jovens com ênfase na saúde sexual. Sampaio e colaboradores (2010) identificaram que os adolescentes não idealizam as unidades de saúde como espaço para o diálogo e orientações, restringindo-se à frequência apenas para tratamento de doenças ou cuidados pontuais. Falta ainda na cultura dos serviços de saúde um espaço destinado à abordagem da sexualidade desvencilhada do foco curativista ou preventivo, ampliando para o paradigma da construção social. Para as autoras citadas, essa dificuldade enfrentada pelas unidades de saúde, de não serem referências para um ambiente de orientação e diálogo para os adolescentes, se relaciona ao modelo centrado no diagnóstico e cura de doenças utilizado nos serviços de atenção básica.

Outro fator destacado que dificulta a relação adolescente-serviço de saúde é a forma como a adolescência é concebida pelos profissionais. Em estudo com enfermeiros e médicos da EqSF de um município do interior paulista, Fonseca e Ozella (2010) observaram que, para os profissionais, a adolescência é concebida por uma visão que considera naturais a insegurança, a vulnerabilidade $\mathrm{e}$ o desequilíbrio, além de ser uma fase conflituosa. Para os autores citados, essa visão dos profissionais dificulta a inserção dos adolescentes nas ações desenvolvidas pelas EqSFs. Nesse contexto, a integração das equipes com a comunidade escolar torna-se uma alternativa para a implementação de práticas efetivas e emancipatórias voltadas à atenção integral à saúde dos adolescentes.

\section{A educação sexual fragilizada pelo despreparo profissional}

A formação e a qualificação profissional há muito tempo são foco de constantes discussões no âmbito da educação brasileira. Os profissionais cada vez mais sentem e alegam despreparo acadêmico e educação permanente insuficiente para a abordagem de diversos temas, dentre eles a sexualidade e a educação sexual (Oliveira e Bueno, 1997; Silva, 2011).

Essa categoria temática emergiu do entrelaçamento dos núcleos de sentido observados nas respostas, que revelaram aspectos relacionados notadamente às dificuldades enfrentadas no cotidiano dos profissionais. No conteúdo das respostas dos participantes, foi possível relacionar núcleos de sentido como o despreparo, a falta de capacitação e a insegurança para a abordagem, os quais para os professores exercem um papel negativo e imobilizador. A esse respeito, Silva (2011, p. 170), ao analisar como a sexualidade e a educação sexual são inseridas no currículo, e qual o seu lugar na formação inicial dos professores, destaca que 
a sexualidade e a orientação sexual se inserem como alternativas, representam um plus na formação, que serão garantidos ou não, na dependência da vontade dos dirigentes dos cursos e dos professores que pretendam atender às exigências da sociedade, pois a atual legislação que trata da formação inicial de professores não aborda este tema entre os seus requisitos. Assim, sob o ponto de vista formal, a sexualidade e a orientação sexual na formação inicial de professores é um não lugar, é algo que não existe ou que só existe enquanto ideal, uma utopia!

Tal realidade evidenciada pelas respostas dos participantes e reforçada pela contribuição de Silva (2011) gera expressiva preocupação de como e quando a escola estará em condições de desenvolver junto aos adolescentes e jovens um programa de educação sexual adequado. As falas de alguns professores refletiram subterfúgios do despreparo, que em determinadas situações levam os profissionais a desviarem do assunto, fingirem que não ouviram determinadas perguntas por não terem um embasamento teórico-científico para suprir a necessidade dos adolescentes e jovens com quem lidam rotineiramente.

Acrescida ao despreparo técnico-científico, há a utilização de valores e crenças pessoais como fonte de informação e orientação para os jovens, o que pode contribuir para uma deseducação (Maia, 2004). Para a autora, o desenvolvimento da temática "pode ser desastrosa se os educadores estiverem despreparados ou forem incapazes de lidar de modo adequado com sua própria sexualidade" (Maia, 2004, p. 169). Ela reforça a importância da sustentação científica e humanista para a abordagem da sexualidade.

Há ainda equívocos no entendimento dos participantes no que diz respeito à definição de gênero. Para eles, o gênero está relacionado aos desejos ou orientação, no sentido de preferência no relacionamento afetivo (heterossexual, homossexual), e não ao "conjunto das representações sociais e culturais construídas a partir da diferença biológica entre os sexos" (Brasil, 1998, p. 321). Os PCNs abordam de forma bastante clara essas representações, possibilitando ao leitor - em especial o educador - melhor entendimento sobre a temática.

Sobre a importância do estudo da sexualidade na formação, Altmann (2013, p. 71) reforça a ideia de que "a sexualidade se tornou objeto de atenção da escola, que passou a produzir um discurso que não é unicamente o da moral, mas também o da racionalidade". Entende ainda que as demandas relativas à sexualidade impliquem mudanças significativas na formação. $\mathrm{O}$ perigo da ausência da educação sexual na formação inicial e permanente é a perpetuação da sexualidade como tabu, porque quando não há abordagem ou discurso, mesmo assim há ensino, pois ainda no silêncio ele existe (Figueiró, 2009).

Entre os profissionais da saúde, as questões da sexualidade fazem parte da formação inicial, porém muito mais voltada para os aspectos biológicos do tema, abstraindo e marginalizando os aspectos da construção social e da educação sexual (Rufino, Madeiro e Girão, 2013; Costa e Coelho, 2011). 
Os profissionais de saúde mostraram-se mais familiarizados com a abordagem da temática, considerando-a como um assunto desmistificado. Entretanto, ainda há evidências de que a formação para essa abordagem é deficiente e que a experiência profissional auxilia no 'desembaraço' para se falar sobre a sexualidade, como evidenciado na fala de S3:

Esse nosso comportamento repressor tem que acabar. Quando eu era mais nova no serviço, era mais fechada; agora, com a experiência, já consigo ser mais aberta.

Altmann (2013), ao fazer uma análise dos desafios para a formação docente sobre a diversidade sexual e a educação, assinala algumas estratégias de viabilização para um processo de educação sobre a temática sexualidade e educação sexual e sua inclusão no currículo para qualificação dos novos professores. Destaca como estratégias a mobilização de eventos, cursos de formação continuada, especializações, pesquisas de pós-graduação, cursos de educação à distância e a exploração do espaço proporcionado por programas do Ministério da Educação, como o Programa Institucional de Bolsas de Iniciação à Docência (Pibid), ligado à Coordenação de Aperfeiçoamento de Pessoal de Nível Superior (Capes), que tem contribuído para a formação inicial de professores (Braibante e Wollmann, 2012).

Essas alternativas que vislumbram aplicações nos setores da saúde e educação podem ser acrescidas à utilização dos equipamentos institucionais gerados pelas políticas e programas de cunho informativo e formativo que já vêm sendo desenvolvidos, como o Programa Saúde na Escola, o Projeto Saúde e Prevenção nas Escolas e as ações propostas nos manuais da atenção básica. Tais publicações atualmente subsidiam a compreensão e o embasamento das políticas públicas brasileiras voltadas aos adolescentes e jovens.

\section{O papel da família na educação sexual: diferentes olhares}

Para os participantes da pesquisa aqui apresentada, a família foi considerada a principal responsável pela educação sexual dos adolescentes e jovens. Entretanto, também a ela foram atribuídas características que dificultam o trabalho, tanto pelo setor saúde como pelo da educação. Os principais aspectos negativos da família foram a falta de conhecimento sobre o assunto para abordar com os filhos e a não aceitação das atividades sobre a temática desenvolvidas pela escola, como exemplificaram as falas a seguir:

A família não tem um conhecimento aprofundado sobre o assunto (P9).

O professor, apesar de ter condições de falar do tema, ele evita porque a família às vezes não aceita (P13). 
O conteúdo das falas destacadas convergiu com os achados de alguns autores (Almeida e Centa, 2009; Almeida, 2008) que apontaram a impotência dos pais para entender o assunto e dialogar sobre a sexualidade com os filhos adolescentes.

Apesar dos aspectos negativos evidenciados, é notório que se pensamos em desenvolver a educação sexual de forma emancipatória, crítica e reflexiva com os adolescentes e jovens, não podemos negligenciar a importância da inserção da família. Moizés e Bueno (2010) consideram a interação família-escola importante para que a sexualidade não sofra interferências da duplicidade de discursos e atitudes, gerada pela perpetuação nos espaços educativos da cisão entre a família e a escola e pela visão mutuamente distorcida da importância de cada ente no processo educativo.

Silva e Megid Neto (2006, p. 193), ao afirmarem que “a família é percebida como não preparada para lidar com a sexualidade e, por isso, precisa ser envolvida no processo", vislumbram a necessidade de que também os pais precisam de um aparato educativo que, aliado com as experiências adquiridas, possibilite melhor continuidade das ações realizadas pela escola e pela EqSF. No âmbito da saúde e educação, o fomento de atividades inclusivas para a família - aqui representada pelos pais ou responsáveis pelos adolescentes e jovens - precisa ser buscado como uma alternativa para o sucesso do trabalho de educação sexual, sobretudo as atividades que de fato valorizem as características positivas dos dois setores. As EqSFs, por estarem inseridas no território, têm o contato com a família de modo mais frequente e facilitado, e o envolvimento com a escola facilitaria também o envolvimento de pais e filhos no processo educativo da sexualidade.

\section{Aproximações e possibilidades do trabalho intersetorial entre saúde e educação}

Essa categoria temática refletiu a contribuição dos professores e profissionais de saúde sobre o desenvolvimento do trabalho intersetorial para a educação sexual. Os núcleos de sentido emergentes da análise das respostas apontaram formas, maneiras e fatores importantes para a efetividade das ações em parceria da saúde com a educação.

Nos dois setores, foi possível observar que as ações conjuntas entre saúde e educação são conceituadas como de grande relevância, em especial quando se pensa o desenvolvimento do trabalho de educação sexual visando à integralidade da atenção aos adolescentes e jovens. A respeito da integralidade, Vilelas Janeiro (2008, p. 389) entende que “o investimento imediato na educação sexual dos adolescentes é um valioso passo no sentido do desenvolvimento sustentado tanto para benefício do indivíduo como da sociedade e da humanidade".

Wimmer e Figueiredo (2006, p. 152) complementam esse raciocínio ao afirmarem que a intersetorialidade é essencial para a "abordagem mais complexa dos problemas" por se caracterizar como uma prática integradora e 
capaz de dar suporte às políticas públicas no cumprimento de seus objetivos. Ao mesmo tempo, a sexualidade e o enfoque à educação sexual se apresentam como problemas complexos dentro dos espaços institucionalizados da saúde e educação, e requerem uma abordagem diferenciada e integradora possibilitada pelas ações intersetoriais.

Nas respostas, foi frequente a sugestão de projetos na escola com participação dos profissionais da saúde, o que nos levou a refletir que, apesar de a temática ser considerada importante por eles, mais importante se torna quando puder ser trabalhada por outros (professores ou profissionais). Valladades (2005) corrobora tal reflexão quando, ao analisar a prática de professores, identificou que a transferência de responsabilidades é frequente nos seus discursos, apesar de considerarem a relevância da temática. A autora pontua que para eles "é extremamente importante que os alunos recebam essas informações [sobre a sexualidade], desde que eles [os professores] não o tenham que fazer" (Valladades, 2005, p. 96).

Para os professores, a participação dos profissionais da saúde no trabalho de orientação na escola ganhou um ar de responsabilização, devido ao caráter imaginário de que os profissionais da saúde (enfermeiros, médicos, psicólogos) são especialistas ou mais bem preparados para esse tipo de abordagem. Ao se considerarem os profissionais de saúde, eles atribuem um peso maior de responsabilização sobre a escola, como pudemos observar na resposta destacada a seguir:

A educação entra no papel de formação e orientações. A saúde entra para prevenir doenças, tanto em relações heterossexuais como homossexuais, prevenir gravidez indesejada e corrigir problemas caso ocorram (S5).

A resposta destacada evidenciou a ideia de complementaridade que o setor saúde tem em relação ao desenvolvimento do trabalho de educação sexual, pautado sobretudo nos aspectos biológicos, patológicos, preventivos e assistenciais, expressos pelos termos 'prevenir' e 'corrigir problemas'. Entretanto, Yara Sayão (1997, p. 115) esclarece que os trabalhos existentes na área de educação sexual não apontam para essa necessidade, pois ela considera que são os próprios profissionais da escola (professores, coordenadores, orientadores) que, na condição de adultos significativos para os alunos, "se constituem interlocutores confiáveis para as questões da sexualidade".

Maia (2004) acrescenta ao posicionamento da outra autora que o profissional mais adequado para a abordagem da sexualidade é, de fato, aquele que realmente se dispõe a estudar e informar sobre os vários aspectos que abrangem a sexualidade, sejam eles biológicos, sejam psicológicos ou sociais. A contribuição que a articulação dos setores oferece reside na possibilidade de ações integradoras, críticas e reflexivas oportunizarem atualização dos educadores para a abordagem do discurso sobre a saúde de forma transversal e interdisciplinar (Maciel et al., 2010). A condição de transferência de res- 
ponsabilidade mostrou-se aqui como um possível fator negativo para uma adequada interação entre os profissionais da saúde e educação, pois dificultaria o compartilhamento e o planejamento das competências de cada setor.

Ao nos debruçarmos sobre os fatores que interferem na implantação de ações intersetoriais no campo da educação sexual, segundo os participantes da pesquisa, a falta de interesse político e de contribuição do Estado como definidor da política pública emergiu com destaque nas respostas. Em contraponto, um profissional da saúde levantou a questão da 'entrega profissional', o que nos levou à reflexão de que mesmo que haja um aparato institucional, contemplado no planejamento local, na disponibilidade de recursos didático-pedagógicos, ainda assim a motivação, a atitude e o comprometimento do profissional podem determinar a efetividade do trabalho.

Em relação às questões envolvendo a participação do Estado, é assertivo afirmar que há atualmente um arcabouço político considerável que fundamenta a prática do trabalho de educação sexual, como a criação dos Parâmetros Curriculares Nacionais, o Programa Saúde na Escola e a Política Nacional de Promoção da Saúde, além de projetos e iniciativas espalhados pelo país. Essas diretrizes vêm constituindo a base para o trabalho intersetorial entre a saúde e a educação. Entretanto, como pontuam Silva e Rodrigues (2010), o que tem dificultado a comunicação entre os diversos setores da sociedade na direção do trabalho intersetorial são as relações de poder existentes entre eles e a estrutura organizacional setorial e fragmentada. Essas características evidenciam a necessidade de se (re)pensarem as práticas vigentes, na busca do "compartilhamento de responsabilidades, poderes e saberes" (Silva e Rodrigues, 2010, p. 768).

Foi notória a percepção - quase que unânime - dos participantes da pesquisa de que a aproximação entre os dois setores para o desenvolvimento da educação sexual seria possível por meio de ações pontuais, sobretudo pelas 'palestras'. É possível que esse procedimento de ensino ainda predomine na percepção dos participantes pelo seu caráter de fácil 'transmissão' de conhecimento, mantendo o aluno na condição de passivo ouvinte e em certas circunstâncias impedindo argumentações e situações embaraçosas ao profissional que, diante do despreparo e pouco envolvimento com a temática, prefere o mínimo de exposição, atendo-se exclusivamente ao caráter biológico da sexualidade.

A esse respeito, Rosely Sayão (1997, p. 104) chama a atenção para a linguagem utilizada na abordagem com os adolescentes e jovens, assinalando que não se fale apenas do corpo, órgãos e funções, mas de "um corpo que tem, quer e faz sexo". Destaca que o corpo está submetido a excitações e que é suporte de vontades; dessa forma, é possível na abordagem proporcionar ao jovem uma visão positiva da sua sexualidade.

Quando na pesquisa idealizamos conhecer as possibilidades para o desenvolvimento da educação sexual de forma intersetorial, pensávamos especialmente em aflorar do ideário dos participantes estratégias que norteassem 
mudanças nas práticas vigentes. Essa contribuição de fato pôde ser observada na resposta de um professor, que contribuiu da seguinte forma:

A escola poderá manter, através do serviço de orientação escolar, a semana da orientação sexual para os jovens. Isso no início do ano letivo, porque nesse período eles estão ainda se conhecendo (P13).

A resposta de $\mathrm{P} 13$ ressaltou a importância da interação entre os estudantes - o 'se conhecendo' nos remete a um tema a ser considerado no ambiente escolar: a corporeidade. Hooks (2000) argumenta que no processo pedagógico os professores atuam em sala como se existisse apenas a mente do aluno, esquecendo-se do corpo. Para a autora, “chamar a atenção para o corpo é trair o legado de repressão e de negação que nos tem sido passado por nossos antecessores na profissão docente" (Hooks, 2000, p. 113).

Para Freire e Dantas (2012, p. 149), "existe uma grande necessidade de se desvendar a importância do corpo na educação". As autoras consideram ainda importante que haja por parte dos educadores o conhecimento sobre a corporeidade e sobre o contexto sociocultural onde as coisas ocorrem, de forma que possibilite aos alunos formar "seus próprios significados de movimentos e linguagem" (Freire e Dantas, 2012, p. 149). Inserir o orientador escolar ou educacional, como sugerido por P13, mostra a possibilidade de uma estratégia importante, mesmo que para uma ação pontual (no início das aulas), mas que pode se tornar uma atividade introdutória para um programa permanente de educação sexual.

Nesta categoria temática foi possível afirmarmos que não há ação intersetorial concreta para o desenvolvimento do trabalho de educação sexual de adolescentes e jovens, quando consideramos os atores envolvidos na pesquisa aqui apresentada. Nos dois setores estudados, há um caminho a ser percorrido, na perspectiva de ultrapassar o discurso e o campo das ideias - lugares onde entendemos estar a intersetorialidade para o desenvolvimento da educação sexual entre os setores.

A produção científica brasileira nos últimos anos tem destacado várias experiências na abordagem da educação sexual, por meio de estratégias e métodos de ensino fundamentados em pensadores como Paulo Freire. Alguns autores (Beserra et al., 2011; Franco e Loureiro, 2012), ao considerarem a abordagem crítico-reflexiva e libertadora proposta por Freire para o processo ensino-aprendizagem, apontam o círculo de cultura como uma estratégia de ensino eficaz para o desenvolvimento do trabalho de educação sexual de adolescentes e jovens na área da saúde e educação. Na visão de Beserra e colaboradores (2011),

o círculo de cultura favorece o aprendizado rápido, contextualizado à realidade dos educandos, existindo uma inter-relação que proporciona liberdade e crítica acerca do assunto abordado, resultando em um grupo mais participativo nos debates, diálogos e trabalhos, como também é utilizado como um itinerário de pesquisa (Beserra et al., 2011, p. 1.564). 
Marinho (2009, p. 51), ao analisar a gênese do círculo de cultura à luz de Paulo Freire (seu criador), pontua que, para ele, o círculo de cultura "era um espaço em que dialogicamente se ensinava e se aprendia, que não havia espaço para transferência de conhecimento, mas a construção do saber do educando em suas hipóteses de leitura de mundo". Apreendendo o conceito de Freire, Beserra e colaboradores (2011), ao investigarem a sexualidade de adolescentes do sexo masculino em uma escola pública de Fortaleza, no estado do Ceará, consideraram o círculo de cultura como um meio eficaz para se trabalharem diversos temas, em especial a sexualidade e a prevenção de DSTs com adolescentes na perspectiva da educação em saúde, capacitando-os a reconhecerem meios de prevenção e repensando condutas. Para o profissional da saúde, em especial o inserido nas equipes de saúde da família, essa estratégia de ensino mostra-se promissora para o trabalho de educação sexual diante da possibilidade da formação de grupos específicos.

Outra contribuição de Paulo Freire e que pode ser utilizada pelos profissionais da saúde e educação é a abordagem problematizadora. Em sua obra, Freire (1987) discute os moldes da educação bancária (opressora) e da educação libertadora (problematizadora), esta pautada no diálogo e na palavra, de forma a permitir que a comunhão entre os homens e com o mundo faça parte do processo de aprendizagem.

Girondi, Nothaft e Mallmann (2006), ao utilizarem a abordagem problematizadora para a educação sexual de adolescentes e jovens em Botucatu (São Paulo), concluíram que o pressuposto freiriano possibilitou que os jovens participassem da construção de um processo educativo que proporcionou a reflexão crítica sobre a autonomia na vivência de uma sexualidade saudável, com respeito a si próprio e ao outro. Alencar e colaboradores (2008), em seu relato de experiências sobre a metodologia problematizadora utilizada pelo enfermeiro na educação sexual de adolescentes em um município do interior de Santa Catarina, assinalaram que a abordagem surtiu efeito positivo importante, uma vez que promoveu mudanças significativas nas concepções e relações pedagógicas, como a valorização do conhecimento dos alunos, da realidade para elaboração do conhecimento, habilidades e atitudes; e estímulo à solução dos problemas, dessa forma favorecendo a cidadania.

Santos (2009) propõe a utilização de filmes como recurso didático-metodológico para as discussões sobre a sexualidade com adolescentes e jovens. A autora acredita que esse recurso pode e dever ser aplicado em várias disciplinas de forma transversal, como preconizam os PCNs, e sua aplicação se estende às EqSFs, pois elas têm a possibilidade de, dentro de suas atividades, formarem grupos de adolescentes e jovens e assim trabalharem coletivamente. Todas essas alternativas didático-metodológicas servem de base para a qualificação dos processos de trabalho de educação sexual realizados pelos profissionais da saúde e educação. 


\section{Considerações finais}

A pesquisa que deu origem a este artigo analisou como o trabalho de educação sexual de adolescentes e jovens é realizado na escola e no serviço de saúde - neste último, com destaque para os profissionais da Estratégia Saúde da Família. Foi possível atingir os objetivos propostos, com a ressalva de que os profissionais não conseguiram de forma mais substancial expressar alternativas para uma articulação entre os setores saúde e educação, uma vez que apenas um professor sugeriu uma atividade para a escola, indicando o orientador educacional como possível organizador.

Conhecer as características pedagógicas e metodológicas utilizadas pelos profissionais da educação (em sala de aula e fora dela) e da saúde (consultas e atividades fora da programação) - um dos objetivos específicos da pesquisa - foi uma descoberta relevante, sobretudo pela contribuição que o estudo pretendeu dar à comunidade, que necessita de informações que lhe possibilitem fazer as melhores escolhas para o alcance de um nível de saúde e educação satisfatório. Dessa forma, conhecer as possibilidades do trabalho intersetorial entre saúde e educação para o desenvolvimento do trabalho de educação sexual foi um fator determinante para o fomento de atividades que possibilitem aos adolescentes e jovens o exercício da sexualidade de forma prazerosa e segura, garantindo seus direitos de cidadania (Andrade, 2004; Montardo, 2008).

Durante a coleta de dados, ficou evidente, em especial com os professores, que falar sobre sexualidade ainda é delicado - fato observado pela não aceitação de vários deles em participar da pesquisa, apesar dos esclarecimentos sobre os objetivos, importância e contribuição do estudo -, o que foi evidenciado pelas esquivas, 'fugas' e até mesmo nas respostas às questões de gênero. $\mathrm{O}$ trabalho de educação sexual nos dois setores era caracterizado por atividades pontuais, fora da programação das disciplinas ou cronograma de atividades e baseado apenas nas demandas vindas dos alunos em sala e dos usuários no serviço de saúde, esquivando-se da característica transversal que é dada à temática dentro dos PCNs.

A vontade de saber dos alunos e usuários foi pontuada como um fator positivo para a realização do trabalho nos dois setores. A família foi indicada pelos participantes como a principal responsável pela abordagem da temática, seguida por escola, igreja, amigos e a mídia. É importante para o sucesso na abordagem do tema que a família seja valorizada e que participe efetivamente das atividades, em especial as de planejamento, para que haja harmonia entre os interesses dos atores envolvidos.

O principal fator que impede uma abordagem permanente da sexualidade nos setores saúde e educação foi o despreparo profissional, tanto na formação inicial como na educação permanente. Consideramos que as iniciativas públicas existentes e novas propostas de educação permanente devem ser potencializadas para que os profissionais que lidam com a sexualidade no cotidiano sintam-se 
aptos a abordá-la com maior segurança. Nesse sentido, a criação de espaços para discussão permanente da temática entre os setores pode ser uma alternativa a ser explorada, principalmente no âmbito do Programa Saúde na Escola.

Ao considerarmos as propostas para a constituição de parceria entre os setores, foi possível notar que a maioria das respostas refletia, de certa forma, as mesmas estratégias que outrora informaram utilizar nas suas abordagens, como palestras, debates, leituras e discussões em sala. Em alguns momentos, vislumbrou-se a elaboração de projetos na escola com a participação dos profissionais da saúde. É necessário, portanto, que ações de educação permanente voltadas à temática da sexualidade sejam formuladas e inseridas no cotidiano do planejamento pedagógico da escola e das ações educativas dos profissionais de saúde inseridos nas EqSFs. Para isso, o envolvimento da gestão nesse planejamento é fundamental, uma vez que as decisões e a definição da política pública estão sob sua alçada.

A intersetorialidade da saúde e da educação como alternativa para o desenvolvimento do trabalho de educação sexual parece ainda flutuar no campo das ideias, transitando apenas nos discursos dos participantes, e amarrada principalmente pela falta de capacidade de desenvolvimento do trabalho e pela rigidez das gestões institucionais. É fundamental, a partir do estudo aqui apresentado, fomentar o discurso e novas análises na perspectiva da sua efetivação como estratégia para que adolescentes e jovens possam vivenciar sua sexualidade de forma plena.

\section{Colaboradores}

Aldrin de Sousa Pinheiro idealizou o estudo em termos teóricos e metodológicos, coletou, analisou e processou os dados, elaborou a discussão dos resultados e redigiu o texto. Lucia Rejane Gomes da Silva e Maria Berenice Alho da Costa Tourinho participaram da orientação metodológica, da versão e da revisão final do texto.

\section{Agradecimento}

À Lívia Julienne da Silva Lima, que contribuiu na revisão do texto final do artigo. 
Resumen La investigación estudió cómo se desarrolla el trabajo de educación sexual de adolescentes y jóvenes desde la perspectiva de la intersectorialidad de salud y educación. Se relevaron las características pedagógicas y metodológicas usadas por profesores y profesionales de la Estrategia Salud de la Familia de un municipio del sur de la Amazonia occidental, así como las perspectivas de intersección de la escuela con los servicios de salud para la educación sexual. La investigación se realizó entre mayo y septiembre de 2013. Se optó por un enfoque cualitativo. Tras una entrevista semiestructurada, se utilizó el análisis de contenido para el relevamiento de las categorías temáticas. El trabajo de educación sexual se caracterizó por actividades puntuales motivadas por la demanda. La familia fue considerada como la principal responsable de la educación sexual, y la falta de preparación profesional se reveló un factor importante para la no realización de este tipo de educación. Las perspectivas intersectoriales indicadas por los participantes estuvieron limitadas a acciones ya existentes en la práctica, como charlas y proyectos, entre otras. La intersectorialidad para el trabajo de educación sexual parece transitar en el campo de las ideas, ligada a los discursos. A pesar de estimuladas por iniciativas gubernamentales, estas perspectivas no han logrado satisfacer la complejidad que involucra su legitimación. Es necesario que se discutan nuevas estrategias para el trabajo de la educación sexual.

Palabras clave sexualidad; educación sexual escolar; políticas públicas; intersectorialidad.

\section{Notas}

${ }^{1}$ Fundação Universidade Federal de Rondônia, Departamento de Enfermagem, Porto Velho, Rondônia, Brasil.

<aldrin.pinheiro@unir.br>

Correspondência: Av. Presidente Dutra, 2.965, Centro, CEP 76801-974, Porto Velho, Rondônia, Brasil.

${ }^{2}$ Fundação Universidade Federal de Rondônia, Departamento de Medicina, Porto Velho, Rondônia, Brasil.

$<$ rejane@unir.br>

${ }^{3}$ Fundação Universidade Federal de Rondônia, Departamento de Administração, Porto Velho, Rondônia, Brasil.

$<$ kang@unir.br>

${ }^{4}$ No estudo aqui apresentado, optamos pela utilização do termo educação sexual a fim de facilitar o entendimento por parte dos leitores. Entretanto, nas citações, foram respeitados os termos que cada autor utilizou.

${ }^{5} \mathrm{O}$ estudo é resultado da dissertação de mestrado A orientação sexual: uma perspectiva de intersetorialidade, de Aldrin de Sousa Pinheiro (2014), apresentada ao Mestrado Profissional em Ensino em Ciências da Saúde, Departamento de Medicina, Fundação Universidade Federal de Rondônia (UNIR). Pesquisa sem financiamento e conflitos de interesses. 


\section{Referências}

ALENCAR, Rúbia A. et al. Desenvolvimento de uma proposta de educação sexual para adolescentes. Ciência \& Educação, Bauru, v. 14, n. 1, p. 159-168, 2008.

ALMEIDA, Ana C. C. H. A enfermeira no contexto da educação sexual dos adolescentes e o olhar da família. 2008. 103f. Dissertação (Mestrado) - Programa de Pós-Graduação em Enfermagem da Universidade Federal do Paraná, Curitiba, 2008.

ALMEIDA, Ana C. C. H.; CENTA, Maria L. A família e a educação sexual dos filhos: implicações para a enfermagem. Acta Paulista de Enfermagem, São Paulo, v. 22, n. 1, p. 71-76, 2009.

ALTMANN, Helena. Orientação sexual nos parâmetros curriculares nacionais. Estudos Feministas, Florianópolis, v. 9, n. 2, p. 575-585, 2001.

ALTMANN, Helena. A sexualidade adolescente como foco de investimento político-social. Educação em Revista, Belo Horizonte, n. 46, p. 287-310, dez. 2007.

ALTMANN, Helena. Diversidade sexual e educação: desafios para a formação docente. Sexualidad, Salud y Sociedad: Revista Latinoamericana, Rio de Janeiro, n. 13, p. 69-82, abr. 2013.

ANDRADE, Luiz O. M. A saúde e o dilema da intersetorialidade. 2004. 364f. Tese (Doutorado em Saúde Coletiva) - Faculdade de Ciências Médicas, Universidade Estadual de Campinas, Campinas, 2004.

AQUINO, Júlio G. Sexualidade na escola: alternativas teóricas e práticas. São Paulo: Summus, 1997.

BARDIN, Laurence. Análise de conteúdo. Lisboa: Edições 70, 2009.

BESERRA, Eveline P. et al. Pedagogia freireana como método de prevenção de doenças. Ciência \& Saúde Coletiva, Rio de Janeiro, v. 16, n. 1, p. 1.563-1.570, 2011.
BRAIBANTE, Maria E. F.; WOLLMANN, Ediane M. A influência do Pibid na formação dos acadêmicos de química licenciatura da UFSM. Química Nova Escola, São Paulo, v. 34, n. 4, p. 167-172, 2012.

BRASIL. Lei n. 8.080, de 19 de setembro de 1990. Dispõe sobre as condições para a promoção, proteção e recuperação da saúde, a organização e o funcionamento dos serviços correspondentes e dá outras providências. Disponível em: <http://www.planalto.gov. br/ccivil_03/leis/L8080.htm>. Acesso em: 23 jun. 2017.

BRASIL. Ministério da Educação. Parâmetros curriculares nacionais: terceiro e quarto ciclos do ensino fundamental - introdução aos parâmetros curriculares nacionais. Brasília: Ministério da Educação e Cultura/Secretaria de Educação Fundamental, 1998.

BRASIL. Ministério da Saúde. Secretaria de Vigilância em Saúde. Departamento de Vigilância Epidemiológica. Guia de vigilância epidemiológica. 7. ed. Brasília: Ministério da Saúde, 2009.

COSTA, Lúcia H. R.; COELHO, Edméia C. A. Enfermagem e sexualidade: revisão integrativa de artigos publicados na Revista Latino-Americana de Enfermagem e na Revista Brasileira de Enfermagem. Revista Latino-Americana de Enfermagem, Ribeirão Preto, v. 19, n. 3, p. 631-639, maio-jun. 2011.

FARIA, Rosane C.; CAMPOS, Estela M. S. Demanda espontânea na Estratégia de Saúde da Família: uma análise dos fatores que a influenciam e os desafios na reordenação do modelo assistencial do SUS. Revista de APS, Juiz de Fora, v. 15, n. 2, p. 148-157, abr.-jun. 2012.

FIGUEIRÓ, Mary N. D. O professor como educador sexual: interligando formação e atuação profissional. In: RIBEIRO, Paulo R. M. Sexualidade e educação: aproximações necessárias. São Paulo: Arte \& Ciência, 2004. p. 153-179. 
FIGUEIRÓ, Mary N. D. Educação sexual: como ensinar no espaço da escola. In: FIGUEIRÓ, Mary N. D. (org.). Educação sexual: múltiplos temas, compromissos comuns. Londrina: UEL, 2009. p. 141-171.

FONSECA, Débora C.; OZELLA, Sérgio. As concepções de adolescência construídas por profissionais da Estratégia de Saúde da Família (ESF). Interface: Comunicação, Saúde e Educação, Botucatu, v. 14, n. 33, p. 411-424, abr.-jun. 2010.

FOUCAULT, Michel. História da sexualidade I: a vontade de saber. 17. ed. Rio de Janeiro: Edições Graal, 2006.

FRANCO, Jussara B.; LOUREIRO, Carlos F. B. Aspectos teóricos e metodológicos do círculo de cultura: uma possibilidade pedagógica e dialógica em educação ambiental. Ambiente \& Educação, Rio Grande, v. 17, n. 1, p. 11-27, 2012.

FREIRE, Ivanilda M.; DANTAS, Maria H. A. Educação e corporeidade: um novo olhar sobre o corpo. Holos, Natal, ano 28, v. 4, p. 148-157, 2012.

FREIRE, Paulo. Pedagogia do oprimido. 17. ed. Rio de Janeiro: Paz e Terra, 1987.

GIRONDI, Juliana B. R.; NOTHAFT, Simone C. S.; MALLMANN, Franciole M. B. A metodologia problematizadora utilizada pelo enfermeiro na educação sexual de adolescentes. Cogitare Enfermagem, Curitiba, v. 11, n. 2, p. 161-165, 2006.

HOOKS, Bell. Eros, erotismo e prática pedagógica. In: LOURO, Guacira L. (org.). O corpo educado: pedagogias da sexualidade. 2. ed. Belo Horizonte: Autêntica, 2000.

INOJOSA, Rose M. Sinergia em políticas e serviços públicos: desenvolvimento social com intersetorialidade. Cadernos Fundap, São Paulo, v. 22, p. 102-110, 2001.

MACIEL, Ethel L. N. et al. Projeto Aprendendo Saúde na Escola: a experiência de repercussões positivas na qualidade de vida e determinantes da saúde de membros de uma comunidade escolar em Vitória, Espírito Santo. Ciência \& Saúde Coletiva, Rio de Janeiro, v. 15, n. 2, p. 389-396, 2010.

MAIA, Ana C. B. Orientação sexual na escola. In: RIBEIRO, Paulo R. M. (org.). Sexualidade e educação: aproximações necessárias. São Paulo: Arte \& Ciência, 2004. p. 153-180.

MARINHO, Andrea R. B. Círculo de cultura: origem histórica e perspectivas epistemológicas. 2009. 127f. Dissertação de Mestrado (Educação) - Faculdade de Educação da Universidade de São Paulo, São Paulo, 2009. Disponível em: <http://www.teses.usp.br/teses/ disponiveis/48/48134/tde-24092009-155120/ pt-br.php>. Acesso em: 8 jan. 2014.

MOIZÉS, Julieta S.; BUENO, Sonia M. V. Compreensão sobre sexualidade e sexo nas escolas segundo professores do ensino fundamental. Revista da Escola de Enfermagem da USP, São Paulo, v. 44, n. 1, p. 205-212, 2010.

MONTARDO, Jorge L. V. Do pecado ao perigo: discursos sobre educação sexual para adolescentes brasileiros no século XX. 2008. 138f. Dissertação (Mestrado em Educação nas Ciências) - Universidade Regional do Noroeste do Estado do Rio Grande do Sul, Ijuí, 2008.

OLIVEIRA, Maria A. F. C.; BUENO, Sonia M. V. Comunicação educativa do enfermeiro na promoção da saúde sexual do escolar. Revista Latino-Americana de Enfermagem, Ribeirão Preto, v. 5, n. 3, p. 71-81, 1997.

PINHEIRO, Aldrin S. A orientação sexual: uma perspectiva de intersetorialidade. 2014. 64f. Dissertação (Mestrado Profissional em Ensino em Ciências da Saúde) - Universidade Federal de Rondônia, Porto Velho, 2014.

RUFINO, Andréa C.; MADEIRO, Alberto P; GIRÃO, Manoel J. B. C. O ensino da sexualidade nos cursos médicos: a percepção de estudantes do Piauí. Revista Brasileira de Educação Médica, Rio de Janeiro, v. 37, n. 2, p. 178-185, 2013. 
SAMPAIO, Juliana et al. Promoção da saúde sexual: desafios no Vale do São Francisco. Psicologia \& Sociedade, Belo Horizonte, v. 22, n. 3, p. 499-506, 2010.

SANTOS, Dayana B. C. Educação sexual na escola: algumas possibilidades didático-metodológicas. In: PARANÁ. Secretaria de Estado da Educação. Superintendência de Educação. Departamento de Diversidade. Núcleo de Gênero e Diversidade Sexual. Sexualidade. Curitiba: SEED-PR, 2009.

SAYÃO, Rosely. Saber o sexo? Os problemas da informação sexual e o papel da escola. In: AQUINO, Júlio G. (org.). Sexualidade na escola: alternativas teóricas e práticas. São Paulo: Summus, 1997. p. 97-105.

SAYÃO, Yara. Orientação sexual na escola: os territórios possíveis e necessários. In: AQUINO, Júlio G. (org.). Sexualidade na escola: alternativas teóricas e práticas. São Paulo: Summus, 1997. p. 107-117.

SILVA, Kênia L.; RODRIGUES, Andreza T. Ações intersetoriais para promoção da saúde na Estratégia Saúde da Família: experiências, desafios e possibilidades. Revista Brasileira de Enfermagem, Brasília, v. 63, n. 5, p. 762-769, set.-out. 2010.

SILVA, Lúcia R. G. Sexualidade e orientação sexual na formação de professores: uma análise da política educacional. Curitiba: CRV, 2011.
SILVA, Regina C. P.; MEGID NETO, Jorge. Formação de professores e educadores para abordagem da educação sexual na escola: o que mostram as pesquisas. Ciência \& Educação, Bauru, v. 12, n. 2, p. 185-197, 2006.

SILVEIRA, Denise T.; CÓRDOVA, Fernanda P. A. A pesquisa científica. In: GERHARDT, Tatiana E.; SILVEIRA, Denise T. (orgs.). Métodos de pesquisa. Porto Alegre: Editora da UFRGS, 2009.

VALLADARES, Katia K. Sexualidade: professor que cala nem sempre consente. Rio de Janeiro: Quartet, 2005.

VILELAS JANEIRO, José M. S. Educar sexualmente os adolescentes: uma finalidade da família e da escola? Revista Gaúcha de Enfermagem, Porto Alegre, v. 29, n. 3, p. 382-390, set. 2008.

WIMMER, Gert F.; FIGUEIREDO, Gustavo O. Ação coletiva para qualidade de vida: autonomia, transdisciplinaridade e intersetorialidade. Ciência \& Saúde Coletiva, Rio de Janeiro, v. 11, n. 1, p. 145-154, 2006.

Recebido em 20/11/2015

Aprovado em 09/03/2017 
